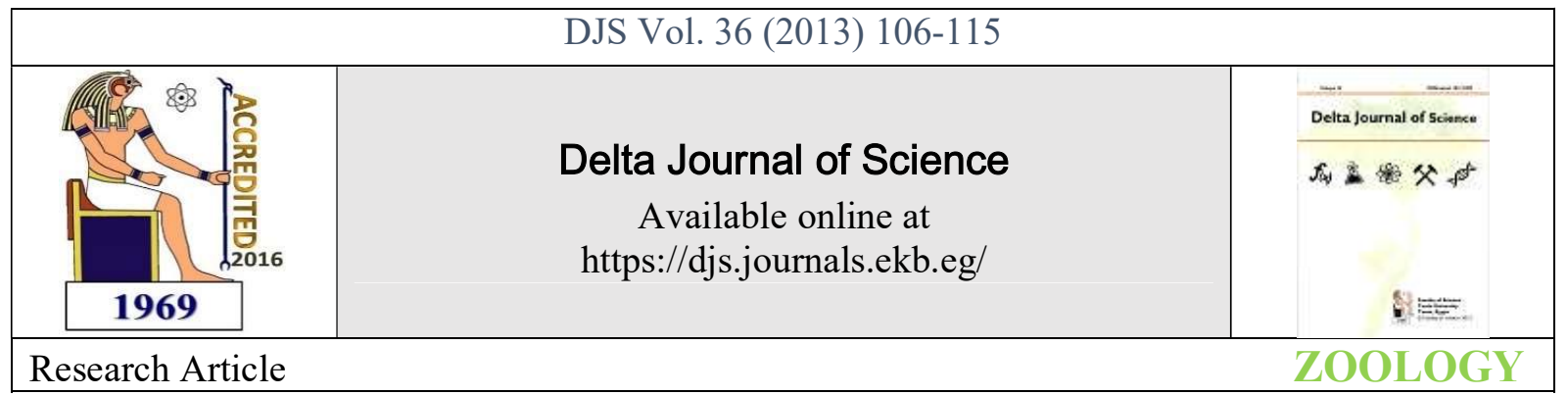

\title{
Protective and curative effect of silymarin against chlorpyrifos-induced immunotoxicity in rats
}

\author{
Ibrahim A. El Elaimy ${ }^{1}$, Hany M. Ibrahim¹, Faten R. Abdel Gafaar ${ }^{1}$, Yahya S. Al-Awthan² \\ ${ }^{1}$ Department of Zoology, Faculty of Science, Minufiya University, Shebin El-Kom, Egypt, ${ }^{2}$ Department of \\ Zoology, Faculty of Science, Ibb University, Yemen.
}

\begin{abstract}
Chlorpyrifos (CPF) is a widely used organophosphorus insecticide throughout the world in agriculture and anti-termites around homes. Silymarin is a naturally occurring substance and has antioxidant effects. For decades, it has been used clinically in Europe for the treatment of alcoholic liver disease and as anti-hepatotoxic agent. Therefore, the present study aimed to assess the protective and curative effect of silymarin in attenuating the CPF-induced immunotoxicity in rats, by measuring the level of immunoglobulin $G$ ( $\operatorname{IgG})$, lymphocyte viability, neutrophil phagocytic function assay, total white blood cells count (WBC) and relative differential white blood cells count, as well as nitric oxide (NO) level and catalase activity. The treatment with CPF decreased lymphocyte viability, neutrophil phagocytic index, total white blood cells count, relative lymphocyte count, IgG concentration and catalase activity. On the other hand, a high level of NO was detected upon animal treatment with CPF. Interestingly, pre- and post-treatment with silymarin to CPF-treated group improved the lymphocyte viability, total white blood cells count, relative lymphocyte count, catalase activity and the NO level. Preand post-treatment with silymarin recovered phagocytic activity of neutrophils and restored $\operatorname{IgG}$ level. In conclusion, silymarin has both protective and curative effects against CPF-induced immunotoxicity may be through its anti-oxidant effects.
\end{abstract}

Keywords: chlorpyrifos, silymarin, nitric oxide, lymphocyte, phagocytosis, IgG.

\section{INTRODUCTION}

Chlorpyrifos $(\mathrm{CPF})$ is an organophosphate $(\mathrm{OP})$ insecticide and it is widely used throughout the world in agriculture and anti-termites agent (Caroline, 1994). CPF is activated to the corresponding oxygen analogue, which is responsible for its toxicity through acetylcholinesterase (AChE) inhibition (Sultatos and Murphy, 1983a,b). OP insecticides induce oxidative stress leading to generation of free radicals and hence increased expressions of oxygen free radical scavenging enzymes in the target tissues (Banerjee et al., 1999; Yarsan et al., 1999; Seth et al., 2000; Banerjee et al., 2001). It is established that reactive oxygen species contribute to organ injury in many systems including the heart, liver and central nervous system (Marubayashi et al., 1985).

OP pesticides including malathion, methylparathion and trichlorphon were reported as immunotoxicants (Ercegovich 1973; Street and Sharma 1975; Galloway and Handy, 2003), inducing thymic atrophy and reductions in splenic germinal centers. Casale et al. (1983) noticed suppression of primary humoral immune responses to a T-cell-dependent antigen in rodents treated orally with cholinergic doses of parathion, malathion, or dimethyl dichlorovinyl phosphate (DDVP). The authors found that the suppression was absent at noncholinergic doses, suggesting that stress may have played a role. Furthermore, Casale et al. (1989) compared several organophosphate compounds for their ability to inhibit human serum complement-mediated lysis of sheep red blood cells (SRBCs).

The mechanisms of OP-induced immunotoxicity may be direct via inhibition of serine hydrolases or esterases in the immune cells, through oxidative damage, or by modulation of signal transduction pathways controlling immune functions (Galloway and Handy, 2003). The indirect effects include modulation of the nervous system, or chronic effects of altered metabolism/nutrition on immune organs (Galloway and Handy, 2003).

In another study which evaluated the effects of CPF on selected functions of immune system in male Fisher 344 rats, CPF was found to impaire T-lymphocyte blastogenesis induced by concanavalin and phytohemagglutinin (Blakley et al., 1999). Also humoral immunity (anti-SRBCs), a Tlymphocyte macrophage-dependent response, was also reduced by CPF (Blakley et al., 1999). On the other hand, CPF increased the relative percentage expression of CD5+ and CD8+ (Blakley et al., 1999). More recent studies showed 
genotoxic and immunotoxic potential of CPF (EL-Elaimy et al., 2008; 2012).

Silymarin, the active complex in milk thistle, is a lipophilic fruit extract and it is composed of several isomer flavonolignans (Ding et al., 2001). For over 30 years, silymarin has been used clinically in Europe for the treatment of alcoholic liver disease and as anti-hepatotoxic agent (Saller et al., 2001). Protective in vitro and in vivo effects against several toxins with different mechanisms of action have been reported (Morazzoni and Bombardelli, 1995). In addition, anti-inflammatory (Miadonna et al., 1987; Manna et al., 1999), antifibrotic (Boigk et al., 1997) and antitumor activities (Singh and Agarwal, 2006) were reported. The essential activity of silymarin is an antioxidant effect of its flavonolignans and of other polyphenolic constituents, which is attributable to the radical scavenging ability toward freeradicals and reactive oxygen species (ROS) (De Groot and Rauen, 1998). Actually, there are no reports of the immunoprotective effects of silymarin against CPF induced toxicity in rats.

Therefore, the aim of the present study was to assess the protective and curative effect of the silymarin on attenuating the CPF-induced toxicity using rat model.

\section{Materials and Methods}

Chlorpyrifos: $\quad$ 0,0-diethyl 0-(3,5,6-trichloro-2-pyridyl) phosphoro-thioate was obtained commercially at a concentration of $48 \%$ from Help Pesticides and Chemical Company, Free zone, New Damietta, Egypt. The desired concentrations were prepared freshly when needed by diluting the pesticide with corn oil.

Silymarin: Silybin $45 \%$ in the form of dry standardized extract of Milk Thistle was purchased from Medical Union Pharmaceuticals, Ismailia, Egypt.

\section{Experimental animals:}

Male albino Wister rats with average weight of $100-120 \mathrm{~g}$ were obtained from the Egyptian Organization for Serology and Vaccination, Ministry of Health, Cairo, Egypt. All animals were kept under controlled laboratory conditions in the animal room, Zoology Department, Faculty of Science, Minufiya University. Animals were housed in standard plastic rodent cages with enough space for their activity. Standard rodent food and clean water were supplied ad libitum. The animals were acclimatized to laboratory condition for at least one week before the initiation of the experiments.

\section{Experimental protocol:}

\section{Exp. 1: PROTECTIVE ACTION OF SILYMARIN:}

The experimental animal ( $\mathrm{n}=10$ rats/group) were divided into four groups as follows:

G (1): Served as a control group orally received vehicle corn oil. Five rats received the vehicle for one week and 5 rats received the vehicle for two weeks.

G (2): Rats were administered orally with $70 \mathrm{mg} / \mathrm{kg} /$ day silymarin (EL-Elaimy et al., 2008). Five rats received the silymarin for one week and 5 rats received the silymarin for two weeks.

G (3): Rats were orally administered $13.5 \mathrm{mg} / \mathrm{kg} /$ day CPF (EL-Elaimy et al., 2012). 5 rats received the CPF for one week and 5 rats received the CPF for two weeks.
G (4): Rats were administered with silymarin $(70 \mathrm{mg} / \mathrm{kg} /$ day) orally, 1 hour before the CPF treatment. Five rats received the silymarin followed by $\mathrm{CPF}$ for one week and 5 rats received the silymarin followed by CPF for two weeks.

All treatments were continued daily and the animals were sacrificed at the end of the $1^{\text {st }}$ or the $2^{\text {nd }}$ week of the treatments.

\section{Exp. 2: CURATIVE EFFECT OF SILYMARIN:}

The experimental animals were divided into two main groups:

$\mathrm{G}$ (1): (10 rats) served as control group and received only vehicle, corn oil.

$\mathrm{G}$ (2): (20 rats) received orally the CPF only $(25 \mathrm{mg} / \mathrm{kg} / \mathrm{twice}$ weekly) for four weeks then, subdivided into two subgroups as follows:

SG (a): (10 rats) received the vehicle alone orally; 5 rats received the vehicle daily for one more week and 5 rats received the vehicle for two weeks.

SG (b): (10 rats) received silymarin $(70 \mathrm{mg} / \mathrm{kg} /$ day) orally; 5 rats received silymarin for one week and 5 rats received silymarin for two weeks

The animals were sacrificed at the end of the $5^{\text {th }}$ or $6^{\text {th }}$ week of the treatment.

\section{Blood and tissue sampling:}

At the end of the designed period, animals were anesthetized with halothane, dissected immediately, and blood was collected from the hepatic portal vein of the rats. Each blood sample was aliquot into two tubes, one was mixed with heparin and the other was permitted to clot. The tubes were centrifuged in a cooling centrifuge at $3000 \mathrm{rpm}$ for $15 \mathrm{~min}$ to separate serum. The separated serum was sampled into clean tubes and kept in a deep-freezer at $-20^{\circ} \mathrm{C}$.

Liver was homogenized $(1: 10, \mathrm{w} / \mathrm{v})$ in ice-cold $100 \mathrm{mM}$ phosphate buffer ( $\mathrm{pH}$ 7.4) using a Potter-Elvehjem homogenizer fitted with a Teflon Plunger. The homogenates were centrifuged at $14,000 \mathrm{xg}$ for $20 \mathrm{~min}$ and the resulting supernatant was kept in a deep-freezer at $-20{ }^{\circ} \mathrm{C}$ till further analyses were performed.

\section{Biochemical parameters:}

Protein content was determined in liver homogenate for the assessment of catalase enzyme according to the method of Lowry et al. (1951). Catalase activity as antioxidant enzyme was determined in the liver homogenate according to the method of Aebi, (1974). The nitric oxide (NO) content of the liver homogenate was determined as nitrite and nitrate by spectrophotometer according to previously described method (Miranda et al., 2001).

\section{Immunological parameter:}

Total leukocytes count (TLC), relative differential white blood cells count; was done manually according to method described by Dacie and Lewis, (1991).

Mononuclear white blood cells (mainly lymphocytes) were isolated from the heparinized blood sample according to the method of Boyum et al. (1968). The viability of lymphocytes was estimated by trypan blue exclusion method (Leffell, 1990). The innate immunity was evaluated by investigating the phagocytic function of the neutrophils. Neutrophils were isolated from the heparinized blood sample according to the method of Markert et al. (1984) and incubated with boiled yeast cells for $30 \mathrm{~min}$ at $37^{\circ} \mathrm{C}$. The tubes were then immersed in ice cold water to stop the reaction. The phagocytic index was estimated by checking the phagocytic cells under ordinary 
light microscope according to the method of (Timothy et al., 1997).

The humoral immunity was evaluated by measuring the level of IgG in the blood serum samples of animals using radial immunodiffusion (RID) plates according to the method of Mancini et al., (1965).

\section{Statistical analysis:}

For statistical analysis the SPSS computer program was used. The statistical analysis was carried out by one-way ANOVA setting the probability level to $P<0.05$, post hoc analysis of group differences was performed by LSD test. The treated groups were compared both with each other and with untreated control groups.

\section{RESULTS}

\section{Catalase activity (CAT):}

Catalase activity exhibited highly significant inhibition $(\mathrm{P}<0.001)$ measured at the $1 \mathrm{st}$ and $2 \mathrm{nd}$ weeks of $\mathrm{CPF}$ treatment when compared to that of the control animals. As shown in Fig. (1A), levels of CAT at the 1st and 2nd week of CPF treatment were $35.14 \pm 1.92$ and $21.34 \pm 3.41$ compared to those of control group $(42.72 \pm 1.80$ and $44.53 \pm 2.00$ respectively). There were no significant differences among the silymarin treated animals compared to the control group. Silymarin pre-treatment to the CPF-intoxicated animals resulted in a significant elevation $(\mathrm{P}<0.001)$ in the catalase activity $(41.27 \pm 2.57,36.86 \pm 3.65)$ when compared to that of the $\mathrm{CPF}$ treated group.

CPF treatment for four weeks caused a significant inhibition $(\mathrm{P}<0.001)$ in the liver catalase activity when compared to that of the control animals. As shown in Fig. (1B), the levels of catalase at the 5th and 6th week of CPF treatment were $25.31 \pm 4.20$ and $29.25 \pm 2.99$, respectively as compared to that of control group (42.85 \pm 1.72 and $42.51 \pm 2.00)$. At the 5 th and 6th week, silymarin post-treatment to the CPF-intoxicated animals resulted in a significant elevation $(\mathrm{P}<0.001)$ in the liver catalase activity $(33.27 \pm 4.18, \quad 39.66 \pm 2.98)$ when compared to that of CPF treated group.
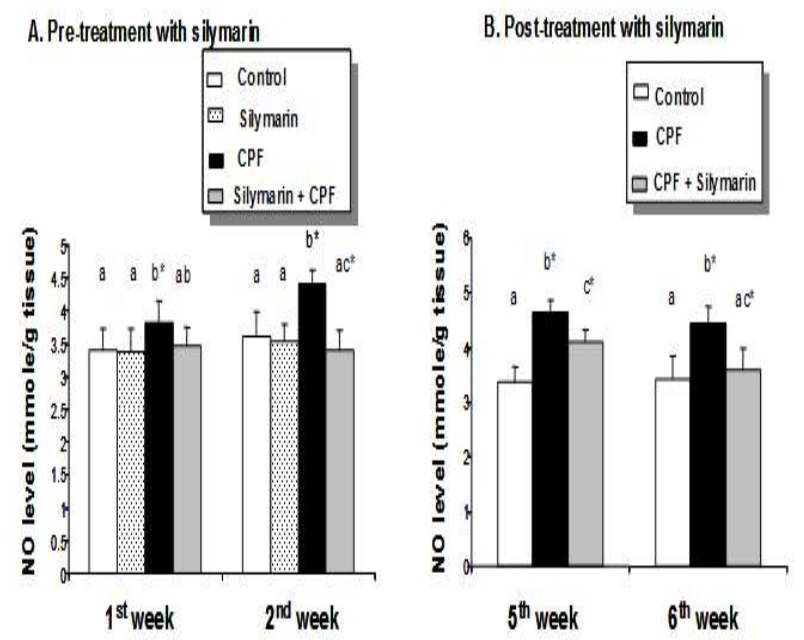

Fig. (2): Liver niric oxide (NO) levels in chlorpyrifos intoxicated male rats pre/post- treated with silymarin.

Number of animals/group $=5$, Data are expressed as: mean \pm standard deviation (SD).

Means assigned with the same letter show insignificant differences between these values.

b Significantly different from controls. c Significantly different from CPF-treated animals.

Significant $*(\mathrm{P}<0.05)$, High significant $* *(\mathrm{P}<0.01)$, and Very high significant $* * *(\mathrm{P}<0.001)$

\section{Total leukocytes count (TLC):}

As shown in Fig. (3A), CPF significantly reduced $(P<0.001)$ the total leukocytes count at the $2^{\text {nd }}$ week of intoxication compared to control group. Furthermore, silymarin pretreatment to $\mathrm{CPF}$-intoxicated animals resulted in a significant elevation $(P<0.001)$ in the total leukocytes number when compared to that of CPF treated group alone. The data also showed that the treatment of rats with silymarin alone for the same period had no significant change in the total leukocytes number when compared to the control group.

Table (1A): Differential leukocytes count in chlorpyrifos intoxicated male rats pre-treated with silymarin.

\begin{tabular}{|c|c|c|c|c|c|}
\hline \multirow[b]{2}{*}{ Parameter } & \multirow{3}{*}{ Groups } & \multicolumn{4}{|c|}{ Treatment Period } \\
\hline & & \multicolumn{2}{|l|}{$1^{\text {st }}$ week } & \multicolumn{2}{|c|}{$2^{\text {nd }}$ week } \\
\hline & & Mean & \pm SD & Mean & $\pm \mathrm{SD}$ \\
\hline \multirow{4}{*}{$\begin{array}{l}\text { LYMPHOCYTES } \\
\text { COUNT }(\%)\end{array}$} & Control & $52.8^{\mathrm{a}}$ & \pm 3.96 & $53.0^{\mathrm{a}}$ & \pm 3.16 \\
\hline & Silymarin & $53.2^{\mathrm{a}}$ & \pm 4.76 & $52.6^{\mathrm{a}}$ & \pm 3.04 \\
\hline & Chlorpyrifos (CPF) & $51.6^{\mathrm{a}}$ & \pm 2.96 & $46.4^{b^{4+4}}$ & \pm 4.03 \\
\hline & Silymarin + CPF & $52.0^{\mathrm{s}}$ & \pm 2.92 & $52.0 \mathrm{x}^{*}$ & \pm 3.80 \\
\hline \multirow{4}{*}{$\begin{array}{l}\text { MONOCYTES } \\
\text { COUNT (\%) }\end{array}$} & Control & $8.2^{\mathrm{s}}$ & \pm 0.83 & $8.8^{\mathrm{s}}$ & \pm 0.84 \\
\hline & Silymarin & $8.6^{\mathrm{a}}$ & \pm 0.89 & $9.0^{\mathrm{a}}$ & \pm 0.70 \\
\hline & Chlorpyrifos (CPF) & $9.0^{\mathrm{s}}$ & \pm 0.71 & $9.6^{\mathrm{a}}$ & \pm 1.14 \\
\hline & Silymarin+ CPF & $9.0^{\mathrm{a}}$ & \pm 1.00 & $8.8^{\mathrm{s}}$ & \pm 0.83 \\
\hline \multirow{4}{*}{$\begin{array}{l}\text { GRANULOCYTES } \\
\text { COUNT }(\%)\end{array}$} & Control & $39.0^{\mathrm{a}}$ & \pm 3.39 & $38.2^{\mathrm{a}}$ & \pm 2.77 \\
\hline & Silymarin & $38.2^{\mathrm{a}}$ & \pm 4.15 & $38.4^{\mathrm{a}}$ & \pm 2.61 \\
\hline & Chlorpyrifos (CPF) & $39.4^{\mathrm{a}}$ & \pm 2.30 & $44.0^{b * *}$ & \pm 3.46 \\
\hline & Silymarin+ CPF & $37.4^{\mathrm{s}}$ & \pm 2.51 & $39.0 \mathrm{x}^{*}$ & \pm 3.56 \\
\hline
\end{tabular}

Number of animals/group $=5$, Data are expressed as: mean \pm standard deviation (SD).

Significant $*(\mathrm{P}<0.05)$, High significant $* *(\mathrm{P}<0.01)$, and Very high significant $* * *(P<0.001)$

Means in the same columns assigned with the same letter show insignificant differences between these values.

After four weeks, CPF intoxication of animals caused a significant decrease $(\mathrm{P}<0.05)$ in the relative lymphocytes count and a significant increase in relative granulocyte counts, without any significant change on the relative monocytes count. Silymarin post-treatment to CPF intoxicated animals showed a remarkable improvement of the over all changes (Table 1B).

Table (1B): Relative differential leukocytes count

\begin{tabular}{|c|c|c|c|c|c|}
\hline \multirow{3}{*}{ Parameter } & \multirow{3}{*}{ Groups } & \multicolumn{4}{|c|}{ Treatment Period } \\
\hline & & \multicolumn{2}{|c|}{$5^{\text {th }}$ week } & \multicolumn{2}{|c|}{$6^{\text {th }}$ week } \\
\hline & & Mean & \pm SD & Mean & $\pm \mathrm{SD}$ \\
\hline \multirow{3}{*}{$\begin{array}{l}\text { LYMPHOCYTES } \\
\text { COUNT }(\%)\end{array}$} & Control & $52.2^{\mathrm{s}}$ & \pm 3.49 & $51.0^{\mathrm{s}}$ & \pm 3.16 \\
\hline & Chlorpyrifos (CPF) & $43.0^{604}$ & \pm 2.83 & $46.4^{\mathrm{s}}$ & \pm 4.04 \\
\hline & CPF+ Silymarin & $49.0 \mathrm{ac}^{*}$ & \pm 3.24 & $52.0 \mathrm{~s}^{*}$ & \pm 3.81 \\
\hline MONOCYTES & Control & $8.6^{\mathrm{s}}$ & \pm 0.90 & $8.6^{\mathrm{s}}$ & \pm 0.89 \\
\hline \multirow{2}{*}{ COUNT (\%) } & Chlorpyrifos (CPF) & $9.4^{\mathrm{a}}$ & \pm 0.55 & $9.6^{\mathrm{s}}$ & \pm 1.14 \\
\hline & CPF+ Silymarin & $9.0^{\mathrm{s}}$ & \pm 1.00 & $8.8^{\mathrm{s}}$ & \pm 0.84 \\
\hline GRANULOCYTES & Control & $39.2^{\mathrm{s}}$ & \pm 2.77 & $40.4^{\mathrm{s}}$ & \pm 2.07 \\
\hline \multirow{2}{*}{ COUNT $(\%)$} & Chlorpyrifos (CPF) & $47.6^{644}$ & \pm 2.79 & $44.0^{\mathrm{s}}$ & \pm 3.46 \\
\hline & CPF+ Silymarin & $42.0 \mathrm{sc}^{4}$ & \pm 3.16 & $39.2 \mathrm{~s}^{*}$ & \pm 3.56 \\
\hline
\end{tabular}


following silymarin post-treatment to male rats intoxicated with chlorpyrifos.

Number of animals/group $=5$, Data are expressed as: mean \pm standard deviation (SD).

Significant * $(\mathrm{P}<0.05)$, High significant ** $(\mathrm{P}<0.01)$, and Very high significant $* * *(\mathbf{P}<\mathbf{0 . 0 0 1})$

Means in the same columns assigned with the same letter show insignificant differences between these values.

\section{Lymphocytes viability:}

As shown in Fig. (4A), CPF significantly reduced $(\mathrm{P}<0.001)$ the viability of lymphocytes at the 2 nd week of intoxication $(78.6 \pm 4.9 \%)$ compared to that of the control group $(92.2 \pm 4.7 \%)$. In contrary, the viability of rat lymphocytes was significantly increased $(\mathrm{P}<0.01)$ upon pre-treatment with silymarin to CPF intoxicated animals $(88.4 \pm 5.3 \%)$ when compared to that of $\mathrm{CPF}$ treated group $(78.6 \pm 4.9 \%)$. The data also showed that treatment of rats with silymarin alone for the same period had no significant change in the lymphocyte viability when compared to those of the control group.

At the 4th week of intoxication, CPF treatment significantly reduced $(\mathrm{P}<0.001)$ the viability of lymphocytes compared to control group (Fig. 4B). Moreover, silymarin post-treatment to $\mathrm{CPF}$ intoxicated animals significantly increased $(\mathrm{P}<0.01)$ the viability of rat lymphocytes when compared to the CPF treated group.
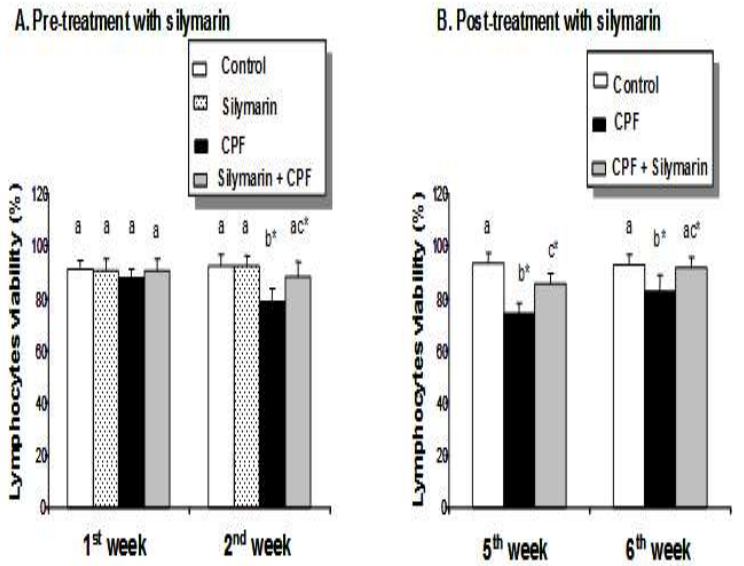

Fig. (4): Lymphocytes viability in chlorpyrifos intoxicated male rats pre/post-treated with silymarin.

Number of animals/group $=5$, Data are expressed as: mean \pm standard deviation (SD). while silymarin post-treatment to CPF intoxicated animals
Means assigned with the same letter show insignificant significantly increased $(\mathrm{P}<0.05)$ and restored the IgG level differences between these values. b Significantly $(10528 \pm 1449 \mathrm{mg} / \mathrm{L})$ when compared to that of CPF treated different from controls. c Significantly different from group. Similar results were obtained at the 5th week of CPF-treated animals.

Significant * $(\mathbf{P}<\mathbf{0 . 0 5})$.

\section{Phagocytic index:}

Fig. (5A), illustrates the effect of $\mathrm{CPF}$ and silymarin on the phagocytic function of neutrophils, expressed as phagocytic index. A significant decrease $(\mathrm{P}<0.01)$ was observed in rats upon the treatment with $\mathrm{CPF}$ at the 2 nd week of intoxication $(64.2 \pm 2.8 \%)$ when compared to control animals $(77 \pm 2.9 \%)$.
On the other hand, silymarin pre-treatment to CPF-treated group significantly increased phagocytic index $(75.4 \pm 2.5 \%)$ when compared to that of $\mathrm{CPF}$ treated group.

At 5th and 6th week, CPF treatment significantly reduced $(\mathrm{P}<0.01)$ the phagocytic index of rat neutrophil $(56.80 \pm 4.15 \%$ and $63.40 \pm 3.36 \%$ ) when compared to control group $(76.20 \pm 3.42 \%$ and $76.20 \pm 3.78 \%)$ respectively, whereas silymarin post-treatment to $\mathrm{CPF}$ intoxicated animals significantly increased $(\mathrm{P}<0.01)$ the phagocytic index $(64.40$ $\pm 3.71 \%, 73.60 \pm 3.97 \%$ ) when compared to the CPF treated group Fig (5B).
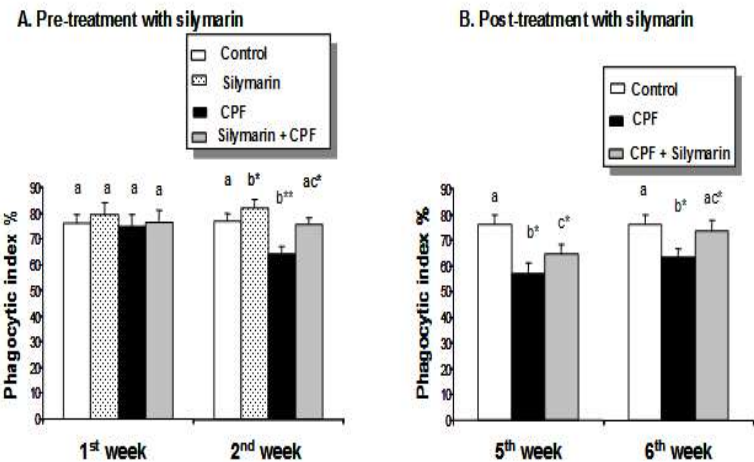

Fig. (5): Phagocytic index in chlorpyrifos intoxicated male rats pre/post-treated with silymarin.

Number of animals/group $=5$, Data are expressed as: mean \pm standard deviation (SD).

Means assigned with the same letter show insignificant differences between these values.

b Significantly different from controls. ${ }^{c}$ Significantly different from CPF-treated animals.

Significant * $(\mathbf{P}<0.05)$ and High significant ** $(\mathbf{P}<0.01)$.

Immunoglobulin G concentration (IgG):

The level of immunoglobulin $\mathrm{G}$ (IgG) in serum of male rats was shown in Fig (6A). The results indicated that CPF alone caused a significant decrease $(\mathrm{P}<0.05)$ in the level of $\operatorname{IgG}$ at the 2 nd week of treatment $(8368 \pm 1192 \mathrm{mg} / \mathrm{L})$ when compared to control animals $(10252 \pm 555 \mathrm{mg} / \mathrm{L})$. On the other hand, pretreatment with silymarin for two weeks improved $(\mathrm{P}<0.05)$ the IgG level $(11900 \pm 848 \mathrm{mg} / \mathrm{L})$ when compared to the CPF group.

As shown in Fig. (6B), At the 6th week of CPF treatment the serum IgG concentration was significantly reduced $(8692 \pm 790$ $\mathrm{mg} / \mathrm{L})$ when compared to control group $(10420 \pm 766 \mathrm{mg} / \mathrm{L})$, treatment.
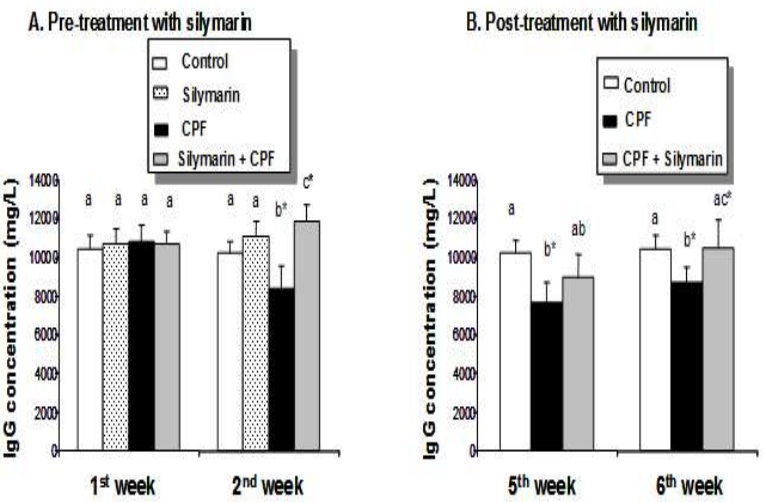
Fig. (6): Serum immunoglobulin $G$ concentration (IgG) in chlorpyrifos intoxicated male rats pre/post-treated with silymarin.

Number of animals/group $=5$, Data are expressed as: mean \pm standard deviation (SD).

Means assigned with the same letter show insignificant differences between these values.

b Significantly different from controls. ' Significantly different from CPF-treated animals.

Significant * $(P<0.05)$ and High significant $* *(P<0.01)$.

\section{Discussion}

The present study investigated the ability of silymarin to modulate the immunotoxic effect of CPF through its antioxidant effects. The present results showed that the treatment with CPF significantly caused an inhibition in the liver CAT and an increase in the liver NO level, while silymarin pre- or post-treatment to CPF-intoxicated animals improved their activities. These results are coincident with those obtained by Goel et al. (2005) who reported that CPF intoxication $(13.5 \mathrm{mg} / \mathrm{kg} / \mathrm{day})$ caused a significant inhibition in the level of CAT activity in the liver of male Wistar rats. Gultekin et al. (2000b) showed that, CPF-ethyl caused an in vitro increase in lipid peroxidation in human erythrocytes. Also, OP insecticides such as phosphomidon, trichlorfon and dichlorvos have been reported to induce an oxidative stress as shown by enhanced malondialdehyde (MDA, a marker of lipid peroxidation) production (Naqvi and Hasan, 1992; Yamano and Morita, 1992).

The low levels of CAT following the CPF treatment could possibly be contributed to the consumption of this enzyme in converting the $\mathrm{H}_{2} \mathrm{O}_{2}$ to $\mathrm{H}_{2} \mathrm{O}$ (Goel et al., 2005). It has been also shown that CAT activity was inhibited by free radicals, such as singlet oxygen and superoxide and peroxyl radicals (Kono and Fridovich, 1982; Escobar et al., 1996). Therefore, CAT may be inhibited by both CPF itself and increased ROS induced by CPF (Gultekin et al., 2006).

The present results also demonstrated that the treatment with CPF significantly increased the liver nitric oxide level and the co-administration of CPF with silymarin significantly inhibits the rise in the level of nitric oxide. These results are in consistence with the previous finding of Bouchaud et al. (1994) who demonstrated that the soman administration at the $\mathrm{LD}_{50}$ led to an increased activity of NO synthase in the cerebral endothelial cells from the $6^{\text {th }}$ hour after poisoning. Crittenden et al. (1998) explained that the methyl parathion increased nitrite production by macrophages in mice treated with 1,3 , or $6 \mathrm{mg} / \mathrm{kg} /$ day. Gupta et al., (2001) reported that the carbamate and OP pesticides caused a significant increase in nitric oxide level of rat brain which related to an increase in citrulline levels while the pretreatment of an antioxidant significantly prevented the increase in the level of citrulline. Furthermore, Zhou et al. (2002) showed that the patients with acute OP pesticide poisoning showed a significant increase in plasma nitric oxide level with a significant decrease in the activities of SOD, CAT and AChE in erythrocytes.

Co-administration of silymarin with $\mathrm{CPF}$ to rats resulted in a marked improvement of the liver CAT and $\mathrm{NO}$ activities when compared to the group which received CPF alone. One of the possible explanations for the observed recovery of various enzyme activities involved in the detoxification following silymarin treatment could be related to its hepatoprotective influence by acting as antioxidant (Ramadan et al., 2002).

Antioxidant effects can be classified into (1) direct action scavenging reactive oxygen species, and (2) the inhibition of the formation of reactive oxygen species (Halliwell, 1995). Gultekin et al. (2000a) showed that adding exogenous antioxidants overcome CPF-ethyl- induced LPO. Previous studies have reported important beneficial effects of silymarin in acute (Muriel and Mourelle 1990a) and chronic (Mourelle et al. 1989; Muriel and Mourelle 1990b) $\mathrm{CCl} 4$ intoxications and in paracetamol overdose (Muriel et al. 1992). Song et al. (2006) showed that silymarin protects against the liver injury caused by acute ethanol administration. The authors suggested that silymarin may be used as an effective therapeutic agent in toxin-induced liver injuries.

Our finding is also in agreement with the results of Soliman and Mazzio, (1998) who proved that silymarin showed a significant suppressive effect of NO production from lipopolysaccharide (LPS)/gamma-interferon (IFN-gamma) stimulated C6 astrocyte cells. Also, Kang et al. (2002) suggested that silymarin inhibits nitric oxide production and inducible nitric oxide synthase (iNOS) gene expression in lipopolysaccharide-stimulated mice macrophages. Another study showed that topical silymarin treatment to mouse skin prevented UV induced immuno-supression where it decreased $\mathrm{H}_{2} \mathrm{O}_{2}$ and nitric oxide production (Katiyar, 2002). It has been found by Lee et al., (2003) that silymarin treatment inhibited the elevation of hepatic iNOS protein content and nitrite concentration in liver homogenate $24 \mathrm{~h}$ after $\mathrm{CCl} 4$ intoxication in rats. Furthermore, Matsuda et al. (2005) showed that silymarin dose-dependently inhibited both cytokine-induced NO production and cell death in IL-1beta and/or interferon (IFN)-gamma-induced beta-cell damage. The inhibition of iNOS by flavonoids may be one of the mechanisms responsible for their anti-inflammatory effects (Raso et al., 2001). Moreover, Wang et al. (2005) tested the hypothesis that silybin can inhibit $\mathrm{H}_{2} \mathrm{O}_{2}$-induced injury in human umbilical vein endothelial cells. The authors reported that silybin decreased the NO contents, restored cell viability with a reduction in $\mathrm{H}_{2} \mathrm{O}_{2}$-induced apoptotic DNA damage, and decreased the expression of caspase- 3 .

Antioxidants are thought to improve immune health by protecting immune and other cells from free radical damage. An adequate intake of antioxidant elements seems to be essential for an efficient function of the immune system (Brambilla et al., 2008). Moreover, maintaining adequate antioxidant status may provide a useful approach in attenuating cell injury and dysfunction observed in some inflammatory disorders (De la Fuente, 2002; De la Fuente et al., 2005).

The results of the present study demonstrated a significant decrease in the total leukocytes count, relative lymphocytes count and a significant increase in relative granulocytes counts in rats treated with $\mathrm{CPF}$ when compared to that of the control group. However, no significant change was demonstrated upon the treatment of silymarin.

These findings are consistent with the results of Goel et al. (2006) who reported that CPF treatment decreased the total leukocytes and lymphocytes count and caused an elevation in the neutrophils count. Neutrophils are the first line of defense against infectious agents, tissue injury, parasites and inflammatory or foreign materials and exert their activity by eliminating foreign material by phagocytosis (Kobayashi et al. 2003). So, the decrease in leukocyte counts by CPF could be attributed either to the slower rate of production of leukocytes or due to their inhibited release into the circulation 
(Goel et al., 2006). A similar decrease in leukocyte counts was observed in rodents intoxicated with another organophosphate, monochrotophos for a long term study (Janardhan and Sisodia 1990). A significant decrease in the total bone marrow cells count was indicated to be a plausible rationale for the observed depression in the total and differential counts of leukocytes of the rats exposed to chronic doses of primiphos-methyl (Rajini et al. 1987). Also, in a study to evaluate haemato- biochemical and immunopathophysiological changes following feeding of broiler chicks with $20 \mathrm{ppm}$ fenvalerate (synthetic pyrethroid), $2 \mathrm{ppm}$ monocrotophos (organophosphate) and $2 \mathrm{ppm}$ endosulfan (chlorinated hydrocarbon), Garg et al. (2004) found that total leukocytes and T-lymphocytes count was lower $(\mathrm{P}<0.01)$ in all treated groups as compared to control group. Recent studies revealed that, leukopenia following CPF treatment, apparently due to lymphopenia, neutropenia, and monocytopenia in the CPF treated animals (Ambali et al., 2007; Ambali et al., 2011; El-Elaimy et al., 2012).

The present results also, demonstrated that silymarin pre- or post-treatment to $\mathrm{CPF}$ intoxicated rats normalized the otherwise altered levels of white blood cell counts when compared to CPF treated alone. These finding are consistent with the results of Goel et al. (2006) who showed that zinc, as antioxidant nutrient, coadministration to $\mathrm{CPF}$ treated animals raised the otherwise decreased total leukocytes count. Also, zinc treatment to the CPF poisoned animals significantly improved the overall lymphocyte and neutrophil counts (Goel et al., 2006). Eugenol, that exhibit anti-oxidant abilities, pretreatment to CPF intoxicated rats restored the altered levels of white blood cell (El- Elaimy et al., 2012).

The present results also, demonstrated a significant reduction in lymphocytes viability in CPF-intoxicated rats compared to those of the control group. Co-exposure of CPF with silymarin restored the cell viability. Many reports have identified two potential cellular targets for $\mathrm{CPF}$, cell signaling cascades from one side and the expression and function of gene transcription factors from the other side (Song et al., 1997; Crumpton et al., 2000b). Reactive oxygen interacts with receptors, second messengers and transcription factors, altering gene expression and influencing cell growth and survival (Palmer and Paulson, 1997). Crumpton et al. (2000a,b) showed that when PC12 cell suspensions were treated acutely with CPF for 10 min, ROS generation was increased in a concentrationdependent manner. The present results are in consistent with previous studies especially that reported by Gultekin et al. (2006) who noticed that CPF decreased the viability of HepG2 cells in a dose dependent manner and the pre-incubation with melatonin prior to CPF application caused an increase in cell viability. Also, Raha et al. (2005) demonstrated that $10 \mathrm{mM}$ $\mathrm{H}_{2} \mathrm{O}_{2}$ produced a significant reduction in viability of cultured human microvascular endothelial cells and the $\mathrm{H}_{2} \mathrm{O}_{2}$-induced alterations were completely prevented by pre-incubating the cells with $10 \mu \mathrm{g} / \mathrm{ml}$ green tea polyphenol for 1 hour.

Phagocytic index showed a significant reduction in CPFintoxicated rats compared to those of the control group. Coexposure of CPF with silymarin recoved the CPF-inhibitory effect on the phagocytic function of neutrophils. In this respect few reports have been done to evaluate the effects of CPF on phagocytosis therefore, the current data come in agreement with the others especially those recorded by Queiroz et al. (1999) who reported that there was a considerable reduction in the ability of neutrophils from exposed workers to carbamate and OP pesticides to kill Candida albicans. In this report the authors concluded that exposure to carbamates and OP insecticides may lead to changes in neutrophils function even in workers presenting no impairment in the cholinesterase (ChE) activity (Queiroz et al. 1999). Also, Wysocki et al.
(1987) showed a significant decrease in the neutrophils activity in workers exposed to OP pesticides as demonstrated using nitroblue-tetrazolium test (NBT) and this reduction was in linear correlation with a reduced $\mathrm{ChE}$ activity.

Similar obtained results were reported by Harford et al. (2005) who demonstrated that endosulfan and CPF caused a significant reduction in the phagocytic function of head kidney cells from four native Australian fish, but the results of endosulfan was more significant than those observed by CPF. Also, Siwicki et al. (1990) reported that trichlorphon an OP insecticide decreased phagocytic ability of neutrophils and in phagocytic index in carp (Cyprinus carpio) at high dose. Moreover, Chang et al. (2006) supported these observed results and reported that phagocytic activity and clearance efficiency to $L$. garvieae significantly decreased when prawns were exposed to 0.2 and $0.4 \mathrm{mg} \mathrm{L}^{-1}$ trichlorfon for $48 \mathrm{~h}$.

The improvement in the phagocytic action in animals pre- or post-treated with silymarin can explained by the data of Tager et al. (2001) who reported an improvement of phagocytosis with a time-dependent increase of intracellular thiols in peritoneal macrophages from dialysis fluid of 30 chronic ambulatory peritoneal dialysis (CAPD) patients treated with silymarin or silibinin up to 35 days. Furthermore, the inhibition of $\mathrm{H}_{2} \mathrm{O}_{2}$ by silybin may be the mechanism by which modulate the leukocytes functions (Minonzio et al., 1988).

Moreover, the present data revealed that CPF significantly decreased the serum immunoglobulin $\mathrm{G}$ ( $\mathrm{IgG})$ concentration; however, the co-adminstration of $\mathrm{CPF}$ with silymarin significantly restored the $\operatorname{IgG}$ level. These results were consistent with some previous reports, Blakley et al. (1999) reported that humoral immunity (anti-sheep red blood cell), a T-lymphocyte macrophage dependent response, was reduced in rats when CPF administered by oral gavage twice weekly for 28 days at a dose of $5.0 \mathrm{mg} / \mathrm{kg}$. Also, Aly and El-Gendy, (2000) found that a single oral dose of dimethoate $(16 \mathrm{mg} / \mathrm{kg})$ significantly decreased serum total immunoglobulins (Ig) and IgM, while IgG was non-significantly deceased. Furthermore, the results of the same study also revealed that dimethoate caused a significant decrease in the number of plaque forming cell (PFC) in a time dependent manner.

Banerjee et al. (1998) showed that sub-chronic doses of malathion exposure caused an attenuation in antigen-induced antibody response, suppression of PFC and induced differential degrees of humoral and cell-mediated immune suppression in male albino mice, rats and rabbits. The organophosphate-induced immunosuppression may result from direct action of acetylcholine upon the immune system or it may be secondary to the toxic chemical stress associated with cholinergic poisoning (Casale et al., 1983).

Kowalczyk-Bronisz et al. (1992) found that the pesticide Chlorfenwinfos exerts immunotropic effect in mice and after high doses the strong suppressive effect in PFC and Erosettes was observed. The significant increased in IgG antibodies following silymarin treatment in $\mathrm{CPF}$-intoxicated animals may be explained by previous study of Walti et al., (1986) showed that flavonoids treatment often induced specific IgG antibodies and less frequently IgE antibodies.

Therefore, it is quite possible to conclude that silymarin, being an antioxidant, might have scavenged the generated free radicals and in turn provided a protection against $\mathrm{CPF}$-induced oxidative stress. In conclusion, CPF immunotoxicity could be protected and cured by the use of silymarin in the experimental animals.

\section{ACKNOWLEDGEMENTS}


The authors deeply thank Prof. Dr. Hassab El-Nabi S. E and Dr. Abd El-Samie, H.A., for their guidance and beneficial help.

\section{References}

Aebi, H. (1974): Catalase. In: Methods of Enzymatic Analysis. Bergemeyer, H. V. (ed.), Public Academic Press, New York, 673- 684.

Aly, N.M. and El-Gendy, K.S. (2000): Effect of dimethoate on the immune system of female mice. J. Environ. Sci. Health., B. 35(1): 77-86.

Ambali S., Akanbi D., Igbokwe N., Shittu M., Kawu M., Ayo J. (2007): Evaluation of subchronic chlorpyrifos poisoning on hematological and serum biochemical changes in mice and protective effect of vitamin C. J Toxicol Sci.;32(2):111-20.

Ambali S.F., Ayo J.O., Esievo K.A., Ojo S.A. (2011): Hemotoxicity induced by chronic chlorpyrifos exposure in wistar rats: mitigating effect of vitamin C. Vet Med Int. 2011:945439.

Banerjee, B.D., Pasha, S.T., Hussain, Q.Z., Koner, B.C., and Ray, A. (1998): A comparative evaluation of immunotoxicity of malathion after subchronic exposure in experimental animals. Ind. J. Exp. Biol., 36(3): 273-282.

Banerjee, B.D., Seth, V., and Ahmed, R.S. (2001): Pesticide induced oxidative stress: perspective and trends. Rev. Environ. Health., 16:1-40.

Banerjee, B.D., Seth, V., Bhattacharya, A., Pasha, S.T., and Chakravorty, A.K.(1999): Biochemical effect of some pesticides on lipid peroxidation and free radical scavengers. Toxicol. Lett., 107:33-47.

Blakley, B.R., Yole, M.J., Brousseau, P., Boermans, H., and Fournier, M. (1999): Effect of chlorpyrifos on immune function in rats. Vet. Hum. Toxicol., 41(3): 140-144.

Boigk, G., Stroedter, L., Herbst, H., Waldschmidt, J., Riecken, EO., Schuppan, D. (1997): Silymarin retards collagen accumulation in early and advanced biliary fibrosis secondary to complete bile duct obliteration in rats. Hepatology. 26(3): 643-649.

Bouchaud, C., Chollat-Namy, A., Duserre, S., Delamanche, I.S.

(1994): The role of nitric oxide in the neuropathology in soman intoxication. Brain. Res. 660(2): 249-254.

Boyum, A. (1968): Separation of leukocytes from blood and bone marrow. Scand. J. Clin. Lab. Invest., 21: Supp, 97:7.

Brambilla, D., Mancuso, C., Scuderi, M.R., Bosco, P., Cantarella, G., Lempereur, L., Di Benedetto, G., Pezzino, S., Bernardini, R. (2008): The role of antioxidant supplement in immune system, neoplastic, and neurodegenerative disorders: a point of view for an assessment of the risk/benefit profile. Nutr J.; 7:29.

Caroline, C. (1994): Chlorpyrifos, Part 1: Toxicology, J. Pest. Ref. 14 (4):15.

Casale, G.P., Bavari, S., and Connolly, J.J. (1989): Inhibition of human serum complement activity by diisopropylfluorophosphate and selected anticholinesterase insecticides. Fund. Appl. Toxicol., 12: 460-468.

Casale, G.P., Cohen, S.D., and DiCapua, R.A. (1983): The effects of organophosphate-induced cholinergic stimulation on the antibody response to sheep erythrocytes in inbred mice. Toxicol. Appl. Pharmacol. 68: 198-205.
Chang, C.C., Lee, P.P., Liu, C.H., Cheng, W. (2006): Trichlorfon, an organophosphorus insecticide, depresses the immune responses and resistance to Lactococcus garvieae of the giant freshwater prawn Macrobrachium rosenbergii. Fish Shellfish Immunol., 20 (4): 574-585.

Crittenden, P.L, Carr, R., Pruett, S.B. (1998): Immunotoxicological assessment of methyl parathion in female B6C3F1 mice. J. Toxicol. Environ. Health. A. 54(1): $1-20$.

Crumpton, T.L., Seidler, F.J., and Slotkin, T.A. (2000a): Is oxidative stress involved in the developmental neurotoxicity of chlorpyrifos? Dev. Brain Res., 121: 189-195.

Crumpton, T.L., Seidler, F.J., and Slotkin, T.A. (2000b): Developmental neurotoxicity of chlorpyrifos in vivo and in vitro: effects on nuclear transcription factors involved in cell replication and differentiation. Brain Res., 857: 87-98.

Dacie, J.V. and Lewis, S.M. (1991): Practical Haematology. Churchill Livingstone UK, 7th Ed

De Groot, H. and Rauen, U. (1998): Tissue injury by reactive oxygen species and the protective effects of flavonoids. Fundam Clin Pharmacol 12(3): 249-255.

De la Fuente, M. (2002): Effects of antioxidants on immune system ageing. Eur J Clin Nutr, 56(Suppl 3):5-8.

De la Fuente, M., Hernanz, A., Vallejo, M.C. (2005): The immune system in the oxidative stress conditions of aging and hypertension: favorable effects of antioxidants and physical exercise. Antioxid Redox Signal, 7(9-10):1356-1366.

Ding, T., Tian, S., Zhang, Z., Gu, D., Chen, Y., Shi, Y., Sun, Z. (2001): Determination of active component in silymarin by RP-LC and LC/MS. J Pharm Biomed Anal. 26(1):155-1561.

El-Elaimy, I.A., Ibrahim, H.M., Abdul Ghaffar, F.R., Alawthan, Y.S. (2012): Evaluation of sub-chronic chlorpyrifos poisoningon immunological and biochemical changes in rats and protective effect of eugenol. Journal of Applied Pharmaceutical Science. 2 (6): 51-61.

El-Elaimy, I.A.; Hassanein, S.E. ; Hassab El -Nabi S.E. ; Alawthan, Y.S. (2008): Induction of DNA damage and expression of hsp70 by chlorpyrifos: ameliorative effects of silymarin and eugenol. Proc. 5th Int. Conf. Biol. Sci. 5: 151157.

Ercegovich, C.D. (1973): Relationships of pesticides to immune responses. Fed. Proc., 32: 2010-2016.

Escobar, J.A., Rubio, M.A., Lissi, E.A. (1996): SOD and catalase inactivation by singlet oxygen and peroxyl radicals. Free Rad. Biol. Med. 20: 285-290.

Galloway T, and Handy R. (2003): Immunotoxicity of organophosphorous pesticides. Ecotoxicology., 12(1-4): 345363.

Garg, U.K., Pal, A.K., Jha, G.J., and Jadhao, S.B. (2004): Haemato-biochemical and immuno-pathophysiological effects of chronic toxicity with synthetic pyrethroid, organophosphate and chlorinated pesticides in broiler chicks. Int Immunopharmacol., 4(13):1709-1722.

Goel, A., Dani, V., and Dhawan, D.K. (2006): Chlorpyrifosinduced alterations in the activities of carbohydrate metabolizing enzymes in rat liver: the role of zinc Toxicol. Lett., 163(3): 235-241.

Goel, A., Dani, V., Dhawan, D.K. (2005): Protective effects of zinc on lipid peroxidation, antioxidant enzymes and hepatic 
histoarchitecture in chlorpyrifos-induced toxicity. ChemicoBiological Interactions 156: 131-140.

Gultekin, F, Delibas, N. Yasar, S., Kiline, I. (2000a): In vivo changes in antioxidant systems and protective role of melatonin and a combination of vitamin $\mathrm{C}$ and vitamin $\mathrm{E}$ on oxidative damage in erythrocytes induced by chlorpyrifosethyle in rats. Arch. Toxicol. 75: 88-96.

Gultekin, F, Ozturk, M. Akdogan, M. (2000b): The effect of organophosphate insecticide chlorpyrifos-ethyl on lipid peroxidation and antioxidant defense system in human fetusan in vitro study. Ind. J. Exp. Biol. 30: 352-354.

Gultekin, F., Patat, S., Akca, H., Akdogan, M., and Altuntas, I. (2006): Melatonin can suppress the cytotoxic effects of chlorpyrifos on human hepG2 cell lines. Hum. Exp. Toxicol., 25(2): 47-55.

Gupta, R.C., Milatovic, D., Dettbarn, W.D. (2001): Nitric oxide modulates high-energy phosphates in brain regions of rats intoxicated with diisopropylphosphorofluoridate or carbofuran: prevention by N-tert-butyl-alpha-phenylnitrone or vitamin E. Arch Toxicol. 75(6): 346-356.

Halliwell, B. (1995): Antioxidant characterization. methodology and mechanism. Biochem Pharmacol. 49 (10): 1341-8.

Harford, A.J, O'Halloran, K., and Wright, P.F. (2005): The effects of in vitro pesticide exposures on the phagocytic function of four native Australian freshwater fish. Aquat. Toxicol., 75(4): 330-342.

Janardhan, A., and Sisodia, P. (1990): Monocrotophos: shortterm toxicity in rats. Bull. Environ. Contam. Toxicol., 44: 230-239.

Kang, J.S., Jeon, Y.J., Kim, H.M., Han, S.H., Yang, K.H. (2002): Inhibition of inducible nitric-oxide synthase expression by silymarin in lipopolysaccharide-stimulated macrophages. J. Pharmacol. Exp. Ther. 302(1): 138-44.

Katiyar, S.K. (2002): Treatment of silymarin, a plant flavonoid, prevents ultraviolet light-induced immune suppression and oxidative stress in mouse skin. Int. J. Oncol. 21(6): 1213-22

Kobayashi, S.D., Voyich, J.M., DeLeo, F.R. (2003): Regulation of the neutrophilmediated inflammatory response to infection. Microbes Infect, 5: 1337-1344.

Kono, Y. and Fridovich, I. (1982): Superoxide radical inhibits catalase. J. Biol. Chem. 257: 5751-5754.

Kowalczyk-Bronisz S, Gieldanowski J, Bubak B, and Kotz J. (1992): Studies on effect of pesticide Chlorfenwinfos on mouse immune system. Arch. Immunol. Ther. Exp., (Warsz). (5-6): 283-289.

Lee, T.Y., Mai, L.M., Wang, G.J., Chiu, J.H., Lin, Y.L., Lin, H.C. (2003): Protective mechanism of salvia miltiorrhiza on carbon tetrachloride-induced acute hepatotoxicity in rats. J. Pharmacol. Sci. 91(3): 202-210.

Leffell, M.S. (1990): Assessment of purity and viability. In: Falk JA, Goeken NE. eds. The ASHI laboratory manual.2nd edition. Lenexa. ASHI. 38.

Lowry, O. H., Rosebrough, N. J., Farr, A. L., Randall, R. J., (1951): Protein measurement with Folin's phenol reagent. J. Biol. Chem. 193: 265-275.

Mancini, G., carbonara, A.O. et al. (1965): Immunochemical quantitation of antigens by single radial immunodiffusion immunochem. 2,235-254.
Manna, S. K., Mukhopadhyay, A., Van, N. T., Aggarwal, B. B. (1999): Silymarin suppresses TNF-induced activation of NF-kB, c-Jun N-terminal kinase and apoptosis. J Immunol. 163: 6800-6809.

Markert, M., Andrews, P. C., and Babior, B. M. (1984): Measurement of $\mathrm{O} 2-$ production by human neutrophils. The preparation and assay of NADPH oxidase-containing particles from human neutrophils. Meth. Enzymol., 105: 358-65.

Marubayashi, S., Dohi, K., Ochi, K., and Kawasaki, T. (1985): Role of free radicals in ischemic rat liver cell injury: prevention of damage by alphatocopherol administration. Surgery, 99: 184- 191

Matsuda, T., Ferreri, K., Todorov, I., Kuroda, Y., Smith, C.V., Kandeel, F., Mullen, Y. (2005): Silymarin protects pancreatic beta-cells against cytokine-mediated toxicity: implication of cJun NH2-terminal kinase and janus kinase/signal transducer and activator of transcription pathways. Endocrinology. 146(1): 175-185.

Miadonna, A., Tedeschi, A., Leggieri, E., Lorini, M., Froldi, M., Zanussi, C. (1987): Effects of silybin on histamine release from human basophil leucocytes.Br J Clin Pharmacol.24(6): $747-752$

Minonzio, F., Venegoni, E., Ongari, A.M., Ciani, D., and Capsoni, F. (1988): Modulation of human polymorphonuclear leukocyte function by the flavonoid silybin. Int. J. Tissue. React., 10 (4): 223-231.

Miranda, K. M., Espey, M. G., Wink, D. A. (2001): A rapid, simple spectrophotometric method for simultaneous detection of Nitrate and nitrite. Nitric oxide: Biology and Chemistry, 5 (1): 62-71.

Morazzoni, P., Bombardelli, E. (1995): Silybum marianum (Carduus marianus). Fitoterapia, LXVI: 3-42

Mourelle, M., Muriel, P., Favari L. and Franco, T. (1989): Prevention of $\mathrm{CCl} 4$ induced liver cirrhosis by silymarin. Fund Clin. Pharmacol., 3: 183-191.

Muriel, P. and Mourelle, M. (1990a): Prevention by silymarin of membrane alterations in acute liver damage. J. Appl. Toxicol., 10: 275-279.

Muriel, P. and Mourelle, M. (1990b): The role of membrane composition in ATPases activities of cirrhotic rats. Effect of silymarin. J. Appl.Toxicol. 10: 281-284.

Muriel, P., Garciapina, V. Pe'rez-Alvarez and Mourelle M. (1992): Silymarin protects against paracetamol-induced lipid peroxidation and liver damage. J. Appl. Toxicol. 12: 439-442.

Naqvi, S. M., Hasan, M. (1992): Acetylhomocysteine thiolactone protection against phosphamidon-induced alteration of regional superoxide dismutase activity in central nervous system and its correlation with altered lipid peroxidation. Ind. J. Exp. Biol. 30: 850-852.

Palmer, H.J., and Paulson, K.E. (1997): Reactive oxygen species and antioxidants in signal transduction and gene expression. Nutr. Rev., 55 (10): 353-61.

Queiroz, M.L., Fernandes, M.D., and Valadares, M.C. (1999): Neutrophil function in workers exposed to organophosphate and carbamate insecticides. Int. J. Immunopharmacol., 21(4): 263-270

Raha, D.K., Hanb, D.W., Hyun Sook Baeka, H.S., Hyond, S.H., and Parkb, J.C. (2005): Prevention of reactive oxygen species-induced oxidative stress in human microvascular endothelial cells by green tea polyphenol. Toxicol. Lett. 155: 269-275. 
Rajini, P.S., Viswanatha, S., and Krishnakumari, M.K. (1987): Effect of pirimiphos-methyl, an organophosphorus insecticide on hematological parameters in albino rats. Indian J Exp Biol 25: 190-193.

Ramadan, L.A., Roushdy, H.M., Abu Senna, G.M., Amin, N.E., El-Deshw, O.A., (2002): Radioprotective effect of silymarin against radiation induced hepatotoxicity. Pharmacol. Res. 45 (6): 447-454.

Raso, G.M., Meli, R., Di Carlo, G., Pacilio, M., Di Carlo, R. (2001): Inhibition of inducible nitric oxide synthase and cyclooxygenase- 2 expression by flavonoids in macrophage J774A.1. Life. Sci. 68 (8): 921-31.

Saller, R., Meier, R., Brignoli, R. (2001): The use of silymarin in the treatment of liver diseases. Drugs. 61(14): 2035-2063.

Seth, V., Banerjee, B.D., Bhattacharya, A., and Chakraborty, A.K. (2000): Lipid peroxidation antioxidant enzymes and glutathione redox systems in blood of human poisoning with propoxur. Clin. Biochem., 33: 683.

Singh, RP., Agarwal, R. (2006): Prostate cancer chemoprevention by silibinin: bench to bedside. Mol Carcinog. 45(6): 436-442.

Siwicki AK, Cossarini-Dunier M, Studnicka M, Demael A. (1990): In vivo effect of the organophosphorus insecticide trichlorphon on immune response of carp (Cyprinus carpio). II. Effect of high doses of trichlorphon on nonspecific immune response. Ecotoxicol. Environ. Saf., 19 (1): 99-105.

Soliman, K.F. and Mazzio, E.A. (1998): In vitro attenuation of nitric oxide production in $\mathrm{C} 6$ astrocyte cell culture by various dietary compounds. Proc. Soc. Exp. Biol. Med. 218(4): 390 397.

Song X, Seidler FJ, Saleh JL, Zhang J, Padilla S, and Slotkin TA. (1997): Cellular mechanisms for developmental toxicity of chlorpyrifos: targeting the adenylyl cyclase signaling cascade. Toxicol. Appl .Pharmacol., 145(1):158-174.

Song, Z., Deaciuc, I., Song, M., Lee, D., Liu, Y., Ji, X. and McClain, C. (2006): Silymarin protects against acute ethanolinduced hepatotoxicity in mice. Alcohol Clin. Exp. Res., 30(3): 407-413.

Street, J.C. and Sharma, R.P. (1975). Alteration of induced cellular and humoral immune responses by pesticides and chemicals of environmental concern: quantitative studies of immunosuppression by DDT, Aroclor 1254, carbaryl, carbofuran, and methylparathion. Toxicol. Appl. Pharmacol., 32: $587-602$.

Sultatos, L. G. and Murphy, S. D. (1983a). Hepatic microsomal detoxification of the organophosphates paraoxon and chlorpyrifos oxon in the mouse, Drug Metab. Dispos., 11: 232-238.

Sultatos, L. G. and Murphy, S. D. (1983b). Kinetic analyses of the microsomal biotransformation of the phosphorothioate insecticides chlorpyrifos and parathion, Fundam. Appl. Toxicol., 3: 16-21.

Tager, M., Dietzmann, J., Thiel, U., Hinrich, Neumann, K., and Ansorge, S. (2001): Restoration of the cellular thiol status of peritoneal macrophages from CAPD patients by the flavonoids silibinin and silymarin. Free. Radic. Res., 34(2):137-51

Timothy, B.H., David, A.M., Pamela, A.F. and George, T.R. (1997): A Cytotoxicity Evaluation of Antimicrobial and NonMicrobial Wound Cleansers. Derma Sciences, 5(1): 1-6.
Walti, M., Neftel, K.A., Jost, R., Jaeger, A., Berg, P., Heinzel, F., and Weitzel, M. (1986): IE and IgG antibodies against flavonoids following therapy with flavonoid-containing drugs. Schweiz. Med. Wochenschr., 116(4): 98-103.

Wang, Y.K., Hong, Y.J., Huang, Z.Q. (2005): Protective effects of silybin on human umbilical vein endothelial cell injury induced by $\mathrm{H} 2 \mathrm{O} 2$ in vitro. Vascul. Pharmacol. 43(4): 198-206.

Wysocki, J., Kalina, Z., and Owczarzy, I. (1987): Effect of organophosphoric pesticides on the behaviour of NBT-dye reduction and $\mathrm{E}$ rosette formation tests in human blood. Int. Arch. Occup. Environ. Health, 59(1): 63-71.

Yamano, T. Morita, S. (1992): Hepatotoxicity of trichlorfon and dichlorvos in isolated rat hepatocytes. Toxicology. 76: 6977.

Yarsan, E., Tanyuksel, M., Celik, S., and Aydin, A. (1999): Effect of aldicarb and malathion on lipid peroxidation. Bull. Environ. Contam. Toxicol., 63: 575-581.

Zhou, J.F., Xu, G.B., Fang, W.J. (2002): Relationship between acute organophosphorus pesticide poisoning and damages induced by free radicals. Biomed Environ Sci. 15(2): 177-186. 


\section{الملخص العربى}

\section{الدور الوقائى والعلاجى للسيليمارين ضد التسمم المناعى المحدث باستخدام الكلوربيريفوس فى الجرزان}

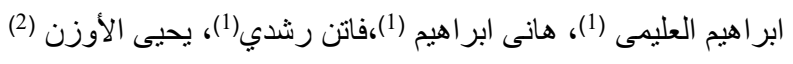

(1) قسم علم الحيو ان، كلية العلوم، جامعة المنوفية، مصر، (2) قسم علم الحيوان، كلية العلوم، جامعة أب اليمن.

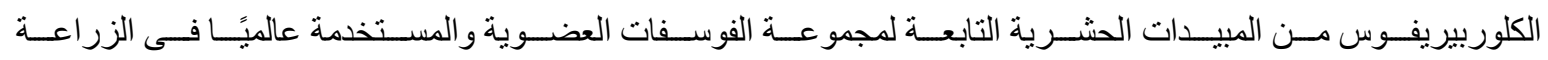

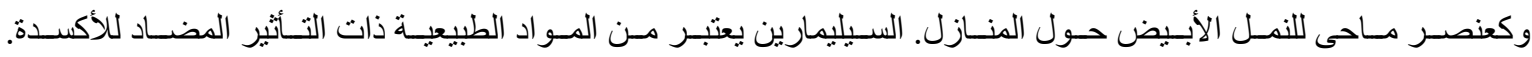

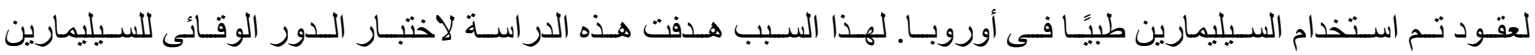

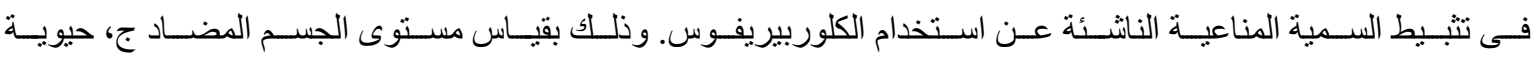

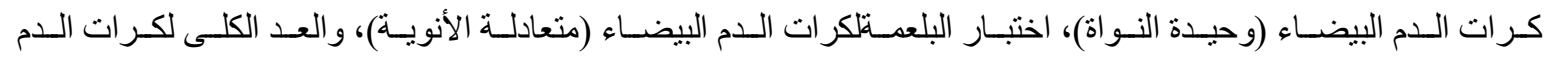

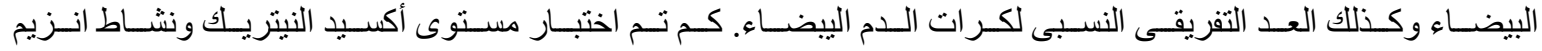

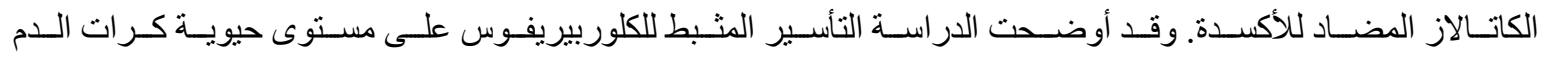

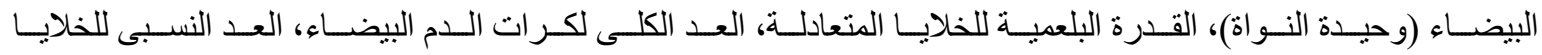

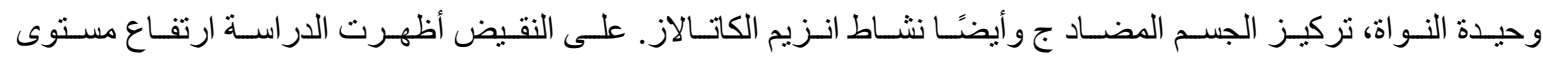

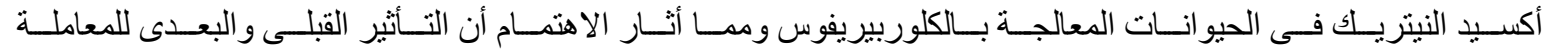

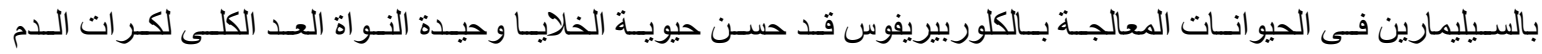

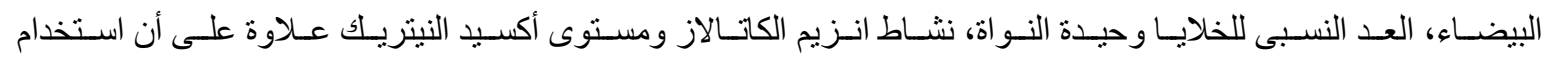

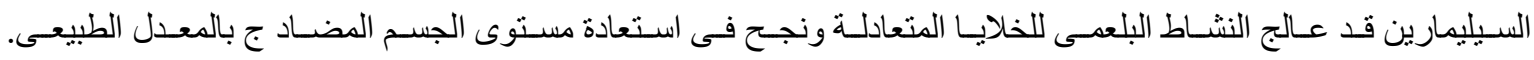

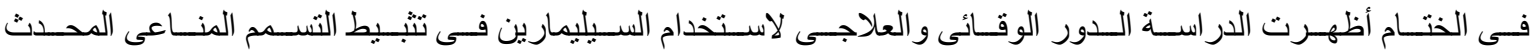

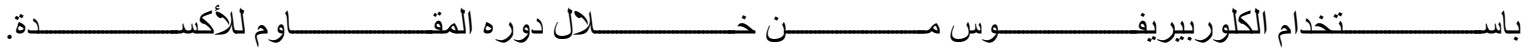

